\title{
Prophylactic Peripheral Blood Stem Cell Collection in Patients with Extensive Bone-Marrow Infiltration of Neuroendocrine Tumours Prior to Peptide Receptor Radionuclide Therapy with ${ }^{177}$ Lu-DOTATATE
}

\author{
Amir Sabet ${ }^{1, *(\mathbb{C},}$, Nicolai Mader ${ }^{1}\left(\mathbb{D}\right.$, Jörg Thomas Bittenbring ${ }^{2}$, Fadi Khreish ${ }^{3}{ }^{\circledR}$, Frank Grünwald ${ }^{1}$, \\ Hans Jürgen Biersack ${ }^{4}$ and Samer Ezziddin ${ }^{3}$ D \\ 1 Department of Nuclear Medicine, University Hospital Frankfurt, 60590 Frankfurt am Main, Germany; \\ nicolai.mader@kgu.de (N.M.); frank.gruenwald@kgu.de (F.G.) \\ 2 Department of Haematology and Oncology, Caritas Hospital Saarbrücken, 66123 Saarbrücken, Germany; \\ Joerg.Thomas.Bittenbring@uks.eu \\ 3 Department of Nuclear Medicine, Saarland University Medical Center, 66421 Homburg, Germany; \\ fadi.khreish@uks.eu (F.K.); samer.ezziddin@uks.eu (S.E.) \\ 4 Department of Nuclear Medicine, University Hospital Bonn, 53127 Bonn, Germany; \\ hans-juergen.biersack@betaklinik.de \\ * Correspondence: amir.sabet@kgu.de
}

Citation: Sabet, A.; Mader, N.; Bittenbring, J.T.; Khreish, F.; Grünwald, F.; Biersack, H.J.; Ezziddin, S. Prophylactic Peripheral Blood Stem Cell Collection in Patients with Extensive Bone-Marrow Infiltration of Neuroendocrine Tumours Prior to Peptide Receptor Radionuclide Therapy with ${ }^{177}$ Lu-DOTATATE. Pharmaceuticals 2021, 14, 1022. https://doi.org/10.3390/ph14101022

Academic Editor: Cristina Müller

Received: 16 July 2021

Accepted: 27 September 2021

Published: 5 October 2021

Publisher's Note: MDPI stays neutral with regard to jurisdictional claims in published maps and institutional affiliations.

Copyright: (c) 2021 by the authors. Licensee MDPI, Basel, Switzerland. This article is an open access article distributed under the terms and conditions of the Creative Commons Attribution (CC BY) license (https:// creativecommons.org/licenses/by/ $4.0 /)$.

\begin{abstract}
Peptide receptor radionuclide therapy (PRRT) of metastatic neuroendocrine tumors (NET) can be successfully repeated but may eventually be dose-limited. Since ${ }^{177}$ Lu-DOTATATE dose limitation may come from hematological rather than renal function, hematological peripheral blood stem cell backup might be desirable. Here, we report our initial experience of peripheral blood stem-cell collection (PBSC) in patients with treatment-related cytopenia and therefore high risk of bone-marrow failure. Five patients with diffuse bone-marrow infiltration of NET and relevant myelosuppression ( $\geq$ grade 2 ) received PBSC before one PRRT cycle with ${ }^{177} \mathrm{Lu}$-DOTATATE (7.6 $\pm 0.8 \mathrm{GBq} /$ cycle). Standard stem-cell mobilization with Granulocyte-colony stimulating factor (G-CSF) was applied, and successful PBSC was defined as a collection of $>2 \times 10^{6} / \mathrm{kg}$ CD34+ cells. In case of initial failure, Plerixafor was administered in addition to G-CSF prior to apheresis. PBSC was successfully performed in all patients with no adverse events. Median cumulative activity was $44.8 \mathrm{GBq}$ (range, 21.3-62.4). Three patients had been previously treated with PRRT, two of which needed the addition of Plerixafor for stem-cell mobilization. Only one of five patients required autologous peripheral blood stem-cell transplantation during the median follow up time of 28 months. PBSC collection seems to be feasible in NET with bone-marrow involvement and might be worth considering as a backup strategy prior to PRRT, in order to overcome dose-limiting bone-marrow toxicity.
\end{abstract}

Keywords: peptide receptor radionuclide therapy; PRRT; neuroendocrine tumor; NET; peripheral blood stem cell collection; PBSC; hematotoxicity

\section{Introduction}

Peptide receptor radionuclide therapy (PRRT) with ${ }^{177}$ Lu-DOTATATE is a longstanding systemic treatment for metastatic gastroenteropancreatic neuroendocrine tumors (GEPNET) [1-3]. Over recent years, several studies have reported remarkable results of individualized PRRT schemes for selected patients in different settings [4-14]. However, the only conducted randomized phase III trial (NETTER-1) demonstrating the efficacy of PRRT was limited to patients with midgut NET receiving a "standard treatment scheme" consisting of four cycles with a predefined administered activity of $7.4 \mathrm{GBq}$ per cycle every 8 weeks [15]. Therefore, identifying other eligible patients for PRRT, appropriate treatment individualizations, and baseline characteristics influencing the outcome mainly relies on 
data from retrospective studies [16-20]. To date, ki67-index $<20 \%$ and limited liver tumor burden are considered as the main favorable prognostic factors for NET patients undergoing PRRT, irrespective of the primary tumor $[8,21,22]$. Patients with advanced metastatic bone involvement, on the other hand, are at higher risk of bone-marrow impairment and are treated cautiously to avoid severe irreversible myelotoxicity [23-25]. In view of the low overall toxicity of PRRT, especially the low nephrotoxic potential of ${ }^{177} \mathrm{Lu}$-DOTATATE, myelosuppression may also be the cumulative dose-limiting toxicity in responsive patients, restricting the application of repeat PRRT cycles [2,26-28].

Autologous peripheral blood stem-cell transplantation is widely used after myeloablative treatments in a variety of hematological malignancies and solid tumors. Peripheral blood is the usual source of stem cells, providing a safe and easily accessible route for isolating autologous stem cells $[29,30]$. Different strategies have been applied to optimize the mobilization and collection of peripheral blood stem cells (PBSC), especially in patients with risk factors for poor mobilization such as bone-marrow involvement [31,32]. To the best of our knowledge, this concept has not yet been considered for PRRT and it remains unclear whether PBSC can be collected in bone metastatic NET disease. If proven successful and safe, autologous transplantation of PBSC may encourage the use of higher activities and more cycles, especially in patients with advanced metastatic disease and very few therapeutic options, increasing the clinical benefit and expanding the indications for PRRT. In this paper we introduce and discuss the feasibility of PBSC collection in NET patients with metastatic bone-marrow spread.

\section{Methods}

Five patients with bone-marrow infiltration of NET and cytopenia on complete blood counts ( $\geq$ grade 2 according to CTCAE v5.0) received PBSC apheresis $8 \pm 4$ weeks before the onset $(n=2)$ or in the interval of two ${ }^{177}$ Lu-DOTATATE administrations $(n=3)$. PRRT was performed with $7.6 \pm 0.8 \mathrm{GBq}{ }^{177} \mathrm{Lu}$-DOTATATE per cycle at standard intervals of 3 months using a previously described protocol [22]. Prior to PBSC, standard stem-cell mobilizing agent granulocyte-colony stimulating factor (G-CSF) was applied subcutaneously at 10 $\mu \mathrm{g} / \mathrm{kg} /$ day for at least 4 days to achieve CD34+ cell counts $\geq 10 / \mu \mathrm{L}$ as the prerequisite for the apheresis. Successful PBSC was defined as $>2 \times 10^{6} / \mathrm{kg}$ CD34+ cells [31]. If adequate numbers of stem cells could not be mobilized, the selective CXCR4 antagonist Plerixafor was added to G-CSF to enhance the outcome $(2,40 \mathrm{mg} / \mathrm{kg}$ s.c., $10 \mathrm{~h}$ before apheresis) $[32,33]$. Table 1 provides tumor- and treatment-related characteristics of the patient cohort.

Table 1. Patients' characteristics and details of PBSC.

\begin{tabular}{|c|c|c|c|c|c|c|c|c|}
\hline \multirow[b]{2}{*}{ Age/Sex } & \multirow[b]{2}{*}{ Prmary/Grade } & \multirow{2}{*}{$\begin{array}{l}\text { Previous } \\
\text { Therapies }\end{array}$} & \multirow{2}{*}{$\begin{array}{c}\text { Metastatic } \\
\text { Site }\end{array}$} & \multirow{2}{*}{$\begin{array}{c}\text { Mobilizing } \\
\text { Agent }\end{array}$} & \multirow{2}{*}{$\begin{array}{c}\text { PBSC } \\
\text { Results }\end{array}$} & \multicolumn{2}{|c|}{ Activity (Cycles) } & \multirow{2}{*}{ Response } \\
\hline & & & & & & $\begin{array}{l}\text { Before } \\
\text { PBSC }\end{array}$ & After PBSC & \\
\hline $60 y / w$ & Ileum/G2 & $\begin{array}{c}\text { CTx } \\
(\text { Dox } / 5 F U) \\
\text { SSA }\end{array}$ & $\begin{array}{l}\text { liver, bone, } \\
\text { LN }\end{array}$ & G-CSF & Successful & $0 \mathrm{GBq}(0)$ & $43.0 \mathrm{GBq}(6)$ & SD \\
\hline $54 y / w$ & Kidney/G2 & $\begin{array}{c}\text { Surgery, SSA, } \\
\text { PRRT }\end{array}$ & bone & G-CSF & Successful & $29.0 \mathrm{GBq}(4)$ & 33.4 GBq (5) & PR \\
\hline $70 \mathrm{y} / \mathrm{m}$ & Jejunum/G1 & $\begin{array}{c}\text { Surgery, SSA, } \\
\text { PRRT }\end{array}$ & liver, bone & $\begin{array}{c}\text { G-CSF, } \\
\text { Plerixafor }\end{array}$ & Successful & 15.7 GBq (2) & $5.6 \mathrm{GBq}(1)$ & PD \\
\hline $53 \mathrm{y} / \mathrm{m}$ & CUP/G2 & $\begin{array}{c}\text { CTx } \\
\text { (Cis/5FU), } \\
\text { Radiation }\end{array}$ & $\begin{array}{l}\text { liver, bone, } \\
\text { LN }\end{array}$ & G-CSF & Successful & $0 \mathrm{GBq}(0)$ & $39.0 \mathrm{GBq}(6)$ & PR \\
\hline $58 y / w$ & Pancreas/G2 & $\begin{array}{c}\text { CTx } \\
\text { (STZ/5FU), } \\
\text { SSA Surgery, } \\
\text { PRRT }\end{array}$ & liver, bone & $\begin{array}{l}\text { G-CSF, } \\
\text { Plerixafor }\end{array}$ & Successful & $37.3 \mathrm{GBq}(5)$ & 7.5 GBq (1) & PR \\
\hline
\end{tabular}

CUP, cancer of unknown origin; SSA, somatostatin receptor analogues; CTx, chemotherapy; STZ, streptozotocin; Dox, doxorubicin; Cis, cisplatin; 5FU, 5-fluorouracil; PRRT, peptide receptor radionuclide therapy. 


\section{Results}

All patients had relevant cytopenia ( $\geq$ grade II) of at least one blood cell line at the time of apheresis. Three patients had anemia (two grade II, and one grade III), two patients had thrombocytopenia (one grade III, and one grade IV), and three patients had leukopenia (one grade II, and two grade III). The median cumulative activity of ${ }^{177} \mathrm{Lu}$-DOTATATE was 44.8 GBq (range, 21.3-62.4; mean, 42.1). PBSC was successfully performed in all five patients. Two of three patients with progressive disease under chemotherapy showed relevant cytopenia at baseline and received PBSC prior to initiation of PRRT, adequate mobilization was achieved in both with G-CSF only. In contrast, two of three patients previously treated with PRRT required additional Plerixafor to achieve $>2 \times 10^{6} / \mathrm{kg}$ CD34+ cells. During the mean follow-up of 28 months, one patient required autologous stem-cell support because of severe cytopenia (thrombocytopenia, grade IV; neutropenia, grade III) 70 days after the completion of PRRT. Blood counts recovered to near normal (grade I thrombocytopenia, normal neutrophil and leukocyte counts) 6 weeks after the procedure. In the other four patients, the harvested PBSC remained stored as back-up material in case of future bone-marrow failure. Figure 1 illustrates 68Ga-DOTATOC PET images of a patient with renal NET treated with $29 \mathrm{GBq}$ 177Lu-DOTATATE prior to PBSC harvesting.
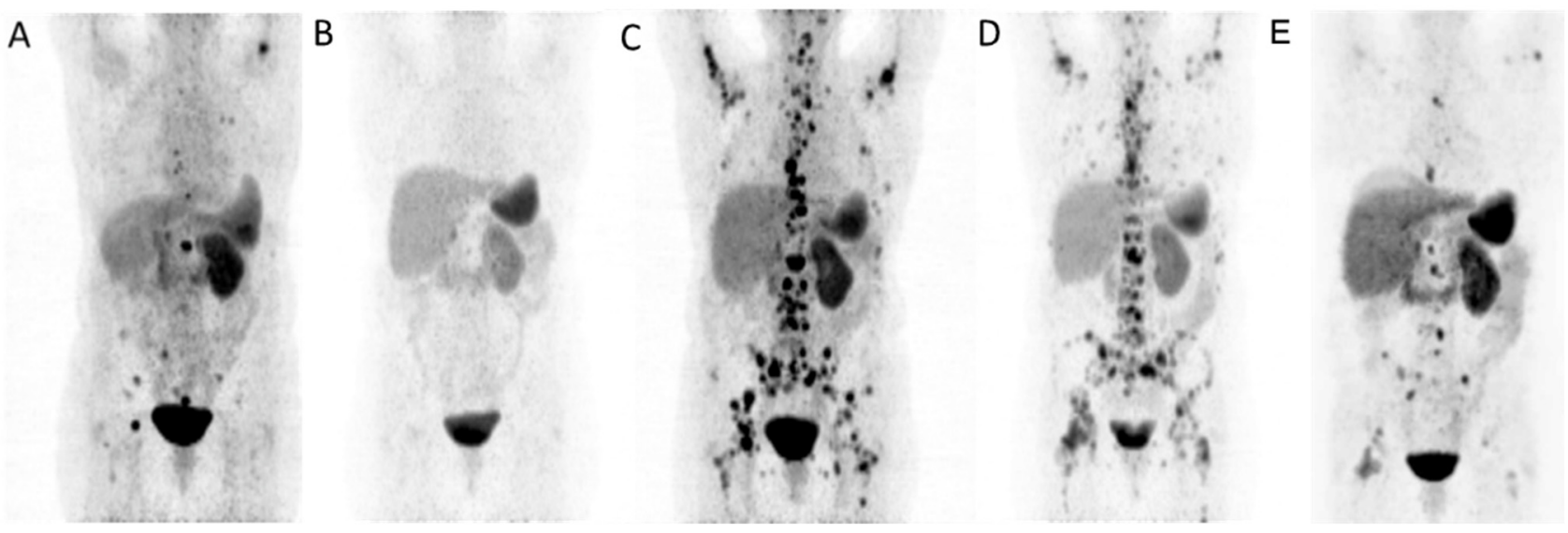

Figure 1. Maximum-intensity-projection ${ }^{68} \mathrm{Ga}$-DOTATOC PET images of a patient with renal NET before (A) and after (B) four cycles of ${ }^{177} \mathrm{Lu}$-DOTATATE $(29 \mathrm{GBq}$ ) showing initial response. Repeat PRRT was performed 14 months later because of progressive disease (C) after successful PBSC harvesting and almost achieved disease stabilization (D) after 2 cycles (15.4 GBq) of re-PRRT and partial response (E) after additional 3 cycles (18 GBq).

\section{Discussion}

This preliminary report introduces the concept of PBSC in high-risk patients with advanced bone-marrow involvement of NET undergoing PRRT, describing a successful procedure in five patients with bone-marrow impairment at the time of apheresis.

Few therapeutic options exist for patients with advanced stage metastatic NET. PRRT with ${ }^{177} \mathrm{Lu}$-DOTATATE is a potent systemic treatment modality for metastatic NET with a low overall toxicity profile. However, the risk of therapy-induced bone-marrow failure restricts the application of sufficiently high activities in patients with extensive bone-marrow infiltration. Similarly, patients with low or decreasing hematological parameters are generally treated with reduced activities, leading to suboptimal treatment outcomes in patients with high tumor load or a clinical need for tumor remission. Patients with significant cytopenia of $\geq$ grade III are often discarded from PRRT [23,25,34]. For a substantial portion of patients with metastatic NET undergoing PRRT, it may persist as a long-term palliative treatment as it can reinduce tumor response once re-progression occurred [16,35-37]. However, cumulative absorbed dose to bone marrow would eventually limit the application $[38,39]$. Moreover, long survival of NET patients allows for the clinical occurrence 
of myelodysplastic syndrome, a potential late sequel of alkylating chemotherapy and systemic radionuclide therapies [40].

If proved feasible in clinical practice, autologous transplantation of PBSC may contribute to overcome the dose-limiting hematotoxicity, allowing dose escalations or repeat PRRT cycles in selected patients. This approach has been successfully used in patients with malignant pheochromocytomas and paragangliomas treated with ${ }^{131}$ I-Metaiodobenzylguan idine ( ${ }^{131}$ I-MIBG). In a phase II study by Fitzgerald et al., PBSC collection at baseline enabled an individualized high-dose treatment with a mean of $833 \mathrm{mCi}(557-1185 \mathrm{mCi})$ in 30 patients. In $4 / 30$ patients, bone-marrow support was needed after the treatment and effectively prevented irreversible myelosuppression [41]. Similarly, in our series, blood counts of the patient with severe cytopenia recovered after autologous peripheral blood stem-cell transplantation.

Hematopoietic growth factors like G-CSF are used for releasing stem cells from the bone marrow into the peripheral blood. The selective CXCR4 antagonist AMD3100 (Plerixafor) [42,43], has been proven to enhance PBSC collection in cancer patients and is established for this purpose, especially in case of mobilization issues [33]. Plerixafor was used in two of our patients to achieve sufficient cell mobilization. Therefore, the most appropriate time point for prophylactic PBSC remains to be determined. Although PBSC would possibly be easier prior to initiation of PRRT [32], collection at later time points (e.g., after two cycles) may facilitate the assessment of risk for developing bone-marrow failure under therapy. In our small cohort, successful PBSC was possible in all patients even after high cumulative activities of ${ }^{177} \mathrm{Lu}$-DOTATATE.

\title{
5. Conclusions
}

Prophylactic PBSC seems technically feasible in patients with advanced bone metastatic NET, even after PRRT with high cumulative activity. The procedure might be worth considering especially in high-risk candidates in an attempt to overcome the dose-limiting hematological toxicity of PRRT.

Author Contributions: Conception of the study: S.E., A.S.; Collection and assembly of data: N.M.; Interpretation of data: J.T.B., A.S.; Drafting of the article: A.S.; Enhancing intellectual content: F.K., H.J.B.; Critical revision of the article for important intellectual content: S.E., N.M., J.T.B., F.G. All authors have read and agreed to the published version of the manuscript.

Funding: This research received no external funding.

Institutional Review Board Statement: All procedures performed in studies involving human participants were in accordance with the ethical standards of the institutional and/or national research committee and with the principles of the 1964 Declaration of Helsinki and its later amendments or comparable ethical standards. This article does not describe any studies with animals performed by any of the authors. Consent was obtained from all individual participants included in the study.

Informed Consent Statement: Consent was obtained from all individual participants included in the study.

Data Availability Statement: Data is contained within the article.

Conflicts of Interest: The authors declare no conflict of interest.

\author{
Abbreviations \\ ${ }^{177} \mathrm{Lu} \quad$ Lutetium-177 \\ CTCAE Common Terminology Criteria for Adverse Events \\ G-CSF Granulocyte-colony stimulating factor \\ NET Neuroendocrine tumor \\ PBSC Peripheral blood stem-cells collection \\ PRRT Peptide receptor radionuclide therapy
}




\section{References}

1. Kwekkeboom, D.J.; de Herder, W.W.; Kam, B.L.; van Eijck, C.H.; van Essen, M.; Kooij, P.P.; Feelders, R.A.; van Aken, M.O.; Krenning, E.P. Treatment with the radiolabeled somatostatin analog [177 Lu-DOTA 0,Tyr3]octreotate: Toxicity, efficacy, and survival. J. Clin. Oncol. 2008, 26, 2124-2130. [CrossRef]

2. Bodei, L.; Kidd, M.; Paganelli, G.; Grana, C.M.; Drozdov, I.; Cremonesi, M.; Lepensky, C.; Kwekkeboom, D.J.; Baum, R.P.; Krenning, E.P.; et al. Long-term tolerability of PRRT in 807 patients with neuroendocrine tumours: The value and limitations of clinical factors. Eur. J. Nucl. Med. Mol. Imaging 2015, 42, 5-19. [CrossRef]

3. Hamiditabar, M.; Ali, M.; Roys, J.; Wolin, E.M.; O’Dorisio, T.M.; Ranganathan, D.; Tworowska, I.; Strosberg, J.R.; Delpassand, E.S. Peptide Receptor Radionuclide Therapy With 177Lu-Octreotate in Patients With Somatostatin Receptor Expressing Neuroendocrine Tumors: Six Years' Assessment. Clin. Nucl. Med. 2017, 42, 436-443. [CrossRef]

4. Yordanova, A.; Wicharz, M.M.; Mayer, K.; Brossart, P.; Gonzalez-Carmona, M.A.; Strassburg, C.P.; Fimmers, R.; Essler, M.; Ahmadzadehfar, H. The Role of Adding Somatostatin Analogues to Peptide Receptor Radionuclide Therapy as a Combination and Maintenance Therapy. Clin. Cancer Res. 2018, 24, 4672-4679. [CrossRef]

5. Yordanova, A.; Ahrens, H.; Feldmann, G.; Brossart, P.; Gaertner, F.C.; Fottner, C.; Weber, M.M.; Ahmadzadehfar, H.; Schreckenberger, M.; Miederer, M.; et al. Peptide Receptor Radionuclide Therapy Combined With Chemotherapy in Patients With Neuroendocrine Tumors. Clin. Nucl. Med. 2019, 44, e329-e335. [CrossRef]

6. Paganelli, G.; Sansovini, M.; Nicolini, S.; Grassi, I.; Ibrahim, T.; Amadori, E.; Di Iorio, V.; Monti, M.; Scarpi, E.; Bongiovanni, A.; et al. (177)Lu-PRRT in advanced gastrointestinal neuroendocrine tumors: 10-year follow-up of the IRST phase II prospective study. Eur. J. Nucl. Med. Mol. Imaging 2021, 48, 152-160. [CrossRef]

7. Sabet, A.; Dautzenberg, K.; Haslerud, T.; Aouf, A.; Sabet, A.; Simon, B.; Mayer, K.; Biersack, H.J.; Ezziddin, S. Specific efficacy of peptide receptor radionuclide therapy with (177)Lu-octreotate in advanced neuroendocrine tumours of the small intestine. Eur. J. Nucl. Med. Mol. Imaging 2015, 42, 1238-1246. [CrossRef]

8. Ezziddin, S.; Opitz, M.; Attassi, M.; Biermann, K.; Sabet, A.; Guhlke, S.; Brockmann, H.; Willinek, W.; Wardelmann, E.; Biersack, H.J.; et al. Impact of the Ki-67 proliferation index on response to peptide receptor radionuclide therapy. Eur. J. Nucl. Med. Mol. Imaging 2011, 38, 459-466. [CrossRef]

9. Delpassand, E.S.; Samarghandi, A.; Zamanian, S.; Wolin, E.M.; Hamiditabar, M.; Espenan, G.D.; Erion, J.L.; O’Dorisio, T.M.; Kvols, L.K.; Simon, J.; et al. Peptide receptor radionuclide therapy with 177Lu-DOTATATE for patients with somatostatin receptor-expressing neuroendocrine tumors: The first US phase 2 experience. Pancreas 2014, 43, 518-525. [CrossRef]

10. Hamiditabar, M.; Ali, M.; Bolek, L.; Vahdati, G.; Tworowska, I.; Delpassand, E.S. Safety and Effectiveness of 177Lu-DOTATATE Peptide Receptor Radionuclide Therapy After Regional Hepatic Embolization in Patients With Somatostatin-Expressing Neuroendocrine Tumors. Clin. Nucl. Med. 2017, 42, 822-828. [CrossRef]

11. Foster, J.H.; Sher, A.; Seghers, V.; Poston, J.; Wells, D.; Delpassand, E.S.; Potter, S.; Mahajan, P.; Venkatramani, R. Peptide receptor radionuclide therapy for treatment of metastatic neuroendocrine tumors in children. Pediatr. Blood Cancer 2021, 68 , e29056. [CrossRef]

12. Braat, A.; Kwekkeboom, D.J.; Kam, B.L.R.; Teunissen, J.J.M.; de Herder, W.W.; Dreijerink, K.M.A.; van Rooij, R.; Krijger, G.C.; de Jong, H.; van den Bosch, M.; et al. Additional hepatic (166)Ho-radioembolization in patients with neuroendocrine tumours treated with (177)Lu-DOTATATE; a single center, interventional, non-randomized, non-comparative, open label, phase II study (HEPAR PLUS trial). BMC Gastroenterol. 2018, 18, 84. [CrossRef]

13. Brabander, T.; van der Zwan, W.A.; Teunissen, J.J.M.; Kam, B.L.R.; Feelders, R.A.; de Herder, W.W.; van Eijck, C.H.J.; Franssen, G.J.H.; Krenning, E.P.; Kwekkeboom, D.J. Long-Term Efficacy, Survival, and Safety of [(177)Lu-DOTA(0),Tyr(3)]octreotate in Patients with Gastroenteropancreatic and Bronchial Neuroendocrine Tumors. Clin. Cancer Res. 2017, 23, 4617-4624. [CrossRef]

14. van Vliet, E.I.; van Eijck, C.H.; de Krijger, R.R.; Nieveen van Dijkum, E.J.; Teunissen, J.J.; Kam, B.L.; de Herder, W.W.; Feelders, R.A.; Bonsing, B.A.; Brabander, T.; et al. Neoadjuvant Treatment of Nonfunctioning Pancreatic Neuroendocrine Tumors with [177Lu-DOTA0,Tyr3] Octreotate. J. Nucl. Med. 2015, 56, 1647-1653. [CrossRef]

15. Strosberg, J.; Krenning, E. 177Lu-Dotatate for Midgut Neuroendocrine Tumors. N. Engl. J. Med. 2017, 376, 1391-1392. [CrossRef]

16. van Essen, M.; Krenning, E.P.; Kam, B.L.; de Herder, W.W.; Feelders, R.A.; Kwekkeboom, D.J. Salvage therapy with (177)Luoctreotate in patients with bronchial and gastroenteropancreatic neuroendocrine tumors. J. Nucl. Med. 2010, 51, 383-390. [CrossRef]

17. Sabet, A.; Haug, A.R.; Eiden, C.; Auernhammer, C.J.; Simon, B.; Bartenstein, P.; Biersack, H.J.; Ezziddin, S. Efficacy of peptide receptor radionuclide therapy with (177)Lu-octreotate in metastatic pulmonary neuroendocrine tumors: A dual-centre analysis. Am. J. Nucl. Med. Mol. Imaging 2017, 7, 74-83.

18. Ezziddin, S.; Khalaf, F.; Vanezi, M.; Haslerud, T.; Mayer, K.; Al Zreiqat, A.; Willinek, W.; Biersack, H.J.; Sabet, A. Outcome of peptide receptor radionuclide therapy with $177 \mathrm{Lu}$-octreotate in advanced grade $1 / 2$ pancreatic neuroendocrine tumours. Eur. J. Nucl. Med. Mol. Imaging 2014, 41, 925-933. [CrossRef]

19. Bodei, L.; Cwikla, J.B.; Kidd, M.; Modlin, I.M. The role of peptide receptor radionuclide therapy in advanced/metastatic thoracic neuroendocrine tumors. J. Thorac. Dis. 2017, 9, S1511-S1523. [CrossRef]

20. Hicks, R.J.; Kwekkeboom, D.J.; Krenning, E.; Bodei, L.; Grozinsky-Glasberg, S.; Arnold, R.; Borbath, I.; Cwikla, J.; Toumpanakis, C.; Kaltsas, G.; et al. ENETS Consensus Guidelines for the Standards of Care in Neuroendocrine Neoplasia: Peptide Receptor Radionuclide Therapy with Radiolabeled Somatostatin Analogues. Neuroendocrinology 2017, 105, 295-309. [CrossRef] 
21. Albertelli, M.; Dotto, A.; Di Dato, C.; Malandrino, P.; Modica, R.; Versari, A.; Colao, A.; Ferone, D.; Faggiano, A.; Nike. PRRT: Identikit of the perfect patient. Rev. Endocr. Metab. Disord. 2021, 22, 563-579. [CrossRef]

22. Ezziddin, S.; Attassi, M.; Yong-Hing, C.J.; Ahmadzadehfar, H.; Willinek, W.; Grunwald, F.; Guhlke, S.; Biersack, H.J.; Sabet, A. Predictors of long-term outcome in patients with well-differentiated gastroenteropancreatic neuroendocrine tumors after peptide receptor radionuclide therapy with 177Lu-octreotate. J. Nucl. Med. 2014, 55, 183-190. [CrossRef]

23. Kwekkeboom, D.J.; Kam, B.L.; van Essen, M.; Teunissen, J.J.; van Eijck, C.H.; Valkema, R.; de Jong, M.; de Herder, W.W.; Krenning, E.P. Somatostatin-receptor-based imaging and therapy of gastroenteropancreatic neuroendocrine tumors. Endocr. Relat. Cancer 2010, 17, R53-R73. [CrossRef]

24. Sabet, A.; Khalaf, F.; Yong-Hing, C.J.; Sabet, A.; Haslerud, T.; Ahmadzadehfar, H.; Guhlke, S.; Grunwald, F.; Biersack, H.J.; Ezziddin, S. Can peptide receptor radionuclide therapy be safely applied in florid bone metastases? A pilot analysis of late stage osseous involvement. Nuklearmedizin 2014, 53, 54-59. [CrossRef]

25. Bergsma, H.; van Lom, K.; Raaijmakers, M.; Konijnenberg, M.; Kam, B.; Teunissen, J.J.M.; de Herder, W.W.; Krenning, E.P.; Kwekkeboom, D.J. Persistent Hematologic Dysfunction after Peptide Receptor Radionuclide Therapy with (177)Lu-DOTATATE: Incidence, Course, and Predicting Factors in Patients with Gastroenteropancreatic Neuroendocrine Tumors. J. Nucl. Med. 2018, 59, 452-458. [CrossRef]

26. Valkema, R.; Pauwels, S.A.; Kvols, L.K.; Kwekkeboom, D.J.; Jamar, F.; de Jong, M.; Barone, R.; Walrand, S.; Kooij, P.P.; Bakker, W.H.; et al. Long-term follow-up of renal function after peptide receptor radiation therapy with (90)Y-DOTA(0),Tyr(3)-octreotide and (177)Lu-DOTA(0), Tyr(3)-octreotate. J. Nucl. Med. 2005, 46 (Suppl. S1), 83-91.

27. Sabet, A.; Ezziddin, K.; Pape, U.F.; Reichman, K.; Haslerud, T.; Ahmadzadehfar, H.; Biersack, H.J.; Nagarajah, J.; Ezziddin, S. Accurate assessment of long-term nephrotoxicity after peptide receptor radionuclide therapy with (177)Lu-octreotate. Eur. J. Nucl. Med. Mol. Imaging 2014, 41, 505-510. [CrossRef]

28. Bergsma, H.; Konijnenberg, M.W.; van der Zwan, W.A.; Kam, B.L.; Teunissen, J.J.; Kooij, P.P.; Mauff, K.A.; Krenning, E.P.; Kwekkeboom, D.J. Nephrotoxicity after PRRT with (177)Lu-DOTA-octreotate. Eur. J. Nucl. Med. Mol. Imaging 2016, 43, 1802-1811. [CrossRef]

29. Mangan, K.F. Peripheral blood stem cell transplantation: From laboratory to clinical practice. Semin. Oncol. 1995, 22, 202-209.

30. Talmadge, J.E.; Reed, E.; Ino, K.; Kessinger, A.; Kuszynski, C.; Heimann, D.; Varney, M.; Jackson, J.; Vose, J.M.; Bierman, P.J. Rapid immunologic reconstitution following transplantation with mobilized peripheral blood stem cells as compared to bone marrow. Bone Marrow Transplant. 1997, 19, 161-172. [CrossRef]

31. Siena, S.; Schiavo, R.; Pedrazzoli, P.; Carlo-Stella, C. Therapeutic relevance of CD34 cell dose in blood cell transplantation for cancer therapy. J. Clin. Oncol. 2000, 18, 1360-1377. [CrossRef]

32. Wuchter, P.; Ran, D.; Bruckner, T.; Schmitt, T.; Witzens-Harig, M.; Neben, K.; Goldschmidt, H.; Ho, A.D. Poor mobilization of hematopoietic stem cells-definitions, incidence, risk factors, and impact on outcome of autologous transplantation. Biol. Blood Marrow Transplant. 2010, 16, 490-499. [CrossRef]

33. Lemoli, R.M.; D'Addio, A. Hematopoietic stem cell mobilization. Haematologica 2008, 93, 321-324. [CrossRef]

34. Kwekkeboom, D.J.; de Herder, W.W.; van Eijck, C.H.; Kam, B.L.; van Essen, M.; Teunissen, J.J.; Krenning, E.P. Peptide receptor radionuclide therapy in patients with gastroenteropancreatic neuroendocrine tumors. Semin. Nucl. Med. 2010, 40, 78-88. [CrossRef]

35. Forrer, F.; Uusijarvi, H.; Storch, D.; Maecke, H.R.; Mueller-Brand, J. Treatment with 177Lu-DOTATOC of patients with relapse of neuroendocrine tumors after treatment with 90Y-DOTATOC. J. Nucl. Med. 2005, 46, 1310-1316. [PubMed]

36. Sabet, A.; Haslerud, T.; Pape, U.F.; Sabet, A.; Ahmadzadehfar, H.; Grunwald, F.; Guhlke, S.; Biersack, H.J.; Ezziddin, S. Outcome and toxicity of salvage therapy with 177Lu-octreotate in patients with metastatic gastroenteropancreatic neuroendocrine tumours. Eur. J. Nucl. Med. Mol. Imaging 2014, 41, 205-210. [CrossRef] [PubMed]

37. van der Zwan, W.A.; Brabander, T.; Kam, B.L.R.; Teunissen, J.J.M.; Feelders, R.A.; Hofland, J.; Krenning, E.P.; de Herder, W.W. Salvage peptide receptor radionuclide therapy with [(177)Lu-DOTA,Tyr(3)]octreotate in patients with bronchial and gastroenteropancreatic neuroendocrine tumours. Eur. J. Nucl. Med. Mol. Imaging 2019, 46, 704-717. [CrossRef] [PubMed]

38. Ezziddin, S.; Sabet, A.; Heinemann, F.; Yong-Hing, C.J.; Ahmadzadehfar, H.; Guhlke, S.; Holler, T.; Willinek, W.; Boy, C.; Biersack, H.J. Response and long-term control of bone metastases after peptide receptor radionuclide therapy with (177)Lu-octreotate. $J$. Nucl. Med. 2011, 52, 1197-1203. [CrossRef]

39. Bergsma, H.; Konijnenberg, M.W.; Kam, B.L.; Teunissen, J.J.; Kooij, P.P.; de Herder, W.W.; Franssen, G.J.; van Eijck, C.H.; Krenning, E.P.; Kwekkeboom, D.J. Subacute haematotoxicity after PRRT with (177)Lu-DOTA-octreotate: Prognostic factors, incidence and course. Eur. J. Nucl. Med. Mol. Imaging 2016, 43, 453-463. [CrossRef] [PubMed]

40. Sabet, A.; Ezziddin, K.; Pape, U.F.; Ahmadzadehfar, H.; Mayer, K.; Poppel, T.; Guhlke, S.; Biersack, H.J.; Ezziddin, S. Long-term hematotoxicity after peptide receptor radionuclide therapy with 177Lu-octreotate. J. Nucl. Med. 2013, 54, 1857-1861. [CrossRef]

41. Fitzgerald, P.A.; Goldsby, R.E.; Huberty, J.P.; Price, D.C.; Hawkins, R.A.; Veatch, J.J.; Dela Cruz, F.; Jahan, T.M.; Linker, C.A.; Damon, L.; et al. Malignant pheochromocytomas and paragangliomas: A phase II study of therapy with high-dose 131Imetaiodobenzylguanidine (131I-MIBG). Ann. N. Y. Acad. Sci. 2006, 1073, 465-490. [CrossRef] [PubMed] 
42. Gerlach, L.O.; Skerlj, R.T.; Bridger, G.J.; Schwartz, T.W. Molecular interactions of cyclam and bicyclam non-peptide antagonists with the CXCR4 chemokine receptor. J. Biol. Chem. 2001, 276, 14153-14160. [CrossRef] [PubMed]

43. Debnath, B.; Xu, S.; Grande, F.; Garofalo, A.; Neamati, N. Small molecule inhibitors of CXCR4. Theranostics $2013,3,47-75$. [CrossRef] [PubMed] 